\title{
Pressure dependence of the equilibrium constant for alkali feldspar - aqueous chloride reactions and activity coefficient ratios of aqueous $\mathrm{KCl} / \mathrm{NaCl}$ at supercritical conditions
}

TARANEH ROODPEYMA AND THOMAS DRIESNER

Swiss Federal Institute of Technology Zürich

Presenting Author: taraneh.roodpeyma@erdw.ethz.ch

Fluid-rock interactions in important geological environments under nominally supercritical pressure-temperature (PT) conditions are difficult to model quantitatively due to a lack of both experimental data and robust thermodynamic models. We re-assess the thermodynamics of the equilibrium between alkali feldspars and aqueous chloride solutions, which has been repeatedly studied (e.g. $[1 ; 2 ; 3])$ :

An analysis of the most comprehensive experimental study [1] at these PT conditions suggests the reported values of equilibrium constant need to be revised as the apparent constancy of aqueous over wide ranges of concentration at a given $\mathrm{T}$ and $\mathrm{P}$ is an artifact. It can be shown that the majority of experiments were carried out within the liquid + vapor twophase region with $>90 \%$ of the aqueous chloride residing in the liquid phase; therefore, almost all measured values essentially report the same high-salinity liquid phase composition. In addition, deriving the equilibrium constant from these high salinity values ignored the need of potentially significant activity corrections and we suggest that values of in the vapor region provide the closest proxy to the true equilibrium constant. We show that there is a significant pressure (or: density) dependence, which has so far largely been ignored. Using these revised equilibrium constants allows tracing the aqueous $\mathrm{NaCl} / \mathrm{KCl}$ activity coefficient ratios as a function of concentration. As the Lagache and Weisbrod (1977) data are insufficient to perform these analyses for temperatures other than $500{ }^{\circ} \mathrm{C}$, we started a new exprimental campaign aiming at water densities of $0.2,0.3,0.4$, and 0.5 for different isotherms ranging from $380,400,450,500{ }^{\circ} \mathrm{C}$ and total chloride concentrations of 0.001 molal (ca $0.006 \mathrm{wt} \%$ ) to $70 \mathrm{wt} \%$. Initial results will be presented.

REFERENCES

[1] Lagache \& Weisbrod (1977), Contrib. Mineral. Petrol. 62, $77-102$.

[2] Orville (1963), Am. J. Sci. 261, 201-237.

[3] Hemley (1967), Abstract, Progr. Ann. Meeting. Geol. Soc. Am., 94-95. 